\title{
Knowledge, attitudes, and behaviors (KAB) related to brushing teeth with powered toothbrush among doctors: a cross-sectional study
}

\section{Yanhao Wang}

College of Stomatology, Chongqing Medical University

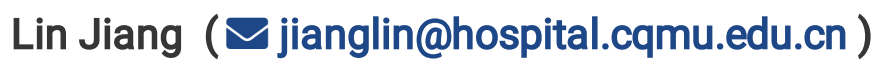

College of Stomatology, Chongqing Medical University

\section{Research article}

Keywords: Knowledge, attitude, behaviors, powered toothbrush, doctors

Posted Date: January 22nd, 2020

DOl: https://doi.org/10.21203/rs.2.21547/v1

License: (c) (1) This work is licensed under a Creative Commons Attribution 4.0 International License.

Read Full License 


\section{Abstract}

Background This study was to explore the knowledge, attitudes, and behaviors (KAB) regarding brushing teeth with powered toothbrush among doctors.

Methods This population-based, cross-sectional study was conducted by using a self-administered questionnaire regarding powered toothbrush based on the KAB model. Multistage cluster sampling was used to enrol doctors.

Results A total of 403 doctors were included in the study. The proportion of "need to be strengthen" on knowledge, attitude and behaviors was 68.0 percent, 71.0 percent and 80.4 percent, respectively. The usage rate of powered toothbrush was low in doctors (12.2 percent). Doctors from dental department had higher knowledge $(p<0.001)$ and attitude $(p<0.01)$ scores than the doctors from non-dental department. Doctors from the district with a higher gross regional product had higher knowledge $(p<0.01)$ and behaviors score $(p<0.001)$, and doctors from higher-level hospitals had higher knowledge $(p<0.001)$. Using powered toothpaste was positively associated with the knowledge $(p<0.001)$, attitude $(p<0.05)$ and behaviors $(p<0.001)$ scores.

Conclusions The majority of doctors' knowledge, attitude and behaviors regarding powered toothbrush were needed to be strengthened. Specific health education is needed to improve the knowledge, attitude and behaviors regarding powered toothbrush.

\section{Background}

As oral diseases which seriously affect human health and quality of life, periodontitis, dental caries and gingivitis are prevalent in the world ${ }^{1-2}$. And for China, according to the fourth Chinese Oral Health Epidemiological Survey, more than eighty percent of adults had different degrees of periodontal diseases, the periodontal condition of middle-aged or old people decreased obviously, and the prevalence rate of caries in children was increased rapidly ${ }^{3}$.

Bacteria can adhere to the surface of hard or soft tissues in the oral cavity, and these common oral diseases are mainly caused by bacterial factors ${ }^{4-8}$. The presence of dental plaque (biofilm) is a necessary condition for the occurrence of dental caries ${ }^{9}$, the teeth with plaque buildup were about 14.5 times more likely to develop dental caries than teeth without dental plaque ${ }^{10}$. Besides, if the population with periodontitis cannot control the dental plaque effectively, the situation of periodontitis will continue to deteriorate ${ }^{11}$, which may lead to the failure of periodontal treatment, and eventually lead to tooth loss 12. Several studies and clinical trials have demonstrated that plaque removal was the key to maintaining long-term health of dental tissue and periodontal tissues ${ }^{13-15}$, therefore, the successful prevention of caries and periodontitis should be achieved by the effective removal of dental plaque. 
Tooth brushing is the most important way to remove dental plaque and prevent caries, gingivitis or periodontitis, and toothbrush is the most widely used tool to clean the plaque in the oral cavity ${ }^{16-17}$. According to the source of power, the toothbrush can be divided into manual toothbrush and powered toothbrush ${ }^{18}$. Although these two types of toothbrushes can achieve the same purposes, such as the removal of plaque and debris or food residue, several evidence-based studies have shown that powered toothbrushes were significantly better than manual toothbrushes in the efficiency of plaque cleaning and the short-term or long-term prevention of gingivitis ${ }^{19-20}$, and powered toothbrushes could be safely used without detailed guidance ${ }^{19}$.

Children may lack motivation, compliance, and adequate manual dexterity with respect to toothbrushing, and when combined with a higher likelihood of sugary/erosive drink consumption, the challenges of cleaning in a mixed dentition and the risk of gingivitis and caries can be notably high ${ }^{21-22}$. Fortunately, the good news is that powered toothbrush was also proved to have greater plaque reduction benefit than the manual toothbrush in children. ${ }^{22-23}$ Moreover, A growing number of studies have shown that many systemic diseases, such as respiratory disease, diabetes, rheumatoid arthritis, chronic kidney disease, obesity and cancer, were closely related to oral microorganism ${ }^{24-26}$, therefore, better tooth brushing does not only contribute to the prevention of oral diseases, but also benefit the overall health. A certain number

of studies have investigated the cognition or use of toothpaste among the public ${ }^{27-30}$, however, to our knowledge, little is known about the cognition or use of powered toothbrush and no studies have focused on the levels of knowledge, attitude and behaviors regarding brushing teeth with powered toothbrush among the public. As the directors of medical work and health education, doctors' knowledge, attitude and behaviors towards health issues will vastly influence the public ${ }^{31-32}$, therefore, the object of this study is the doctor.

Health survey can provide information and evidence for the promotion of public health ${ }^{33}$. Therefore, the purpose of this study is to describe the knowledge, attitude and behaviors of doctors towards brushing teeth with powered toothbrush and provide some information for health education and further studies.

\section{Methods}

\section{Participants}

This cross-sectional study was conducted in Chongqing, China, from July to August in 2017, using multistage cluster sampling method to enroll participants. The 40 districts or counties of Chongqing are divided into five levels, according to the gross regional product of 2016. In the first stage of sampling, one district or county from each of the five levels was randomly chosen, and finally, Yuzhong, Banan, Qijiang, Fengdu, and Wulong were chosen. In the second stage of sampling, one town or block were selected randomly from each of the five districts or counties chosen in the first stage. All the dentists and nondental dentists (NDDs) from all the legal hospitals or clinics in the selected towns or blocks were asked if he or she would like to participant in the study. A total of 437 doctors were asked if they would like to 
participate the study, of whom 403 doctors ( 243 doctors were from non-dental departments and 160 were dentists) completed the questionnaires.

\section{Study design}

The self-administered questionnaire was particularly designed for the study population (doctors) based on the knowledge-attitude-behavior (KAB) model ${ }^{34}$, it included four parts: (1) Demographic characteristics (2) Knowledge related to brushing teeth with powered toothbrush (3) Attitude related to brushing teeth with powered toothbrush (4) Behaviors related to brushing teeth with powered toothbrush.

Prior to the implementation of this study, the questionnaire was piloted with 37 doctors ( 15 dentists and 22 non-dental doctors), revisions were made accordingly, and after the repeated discussions with experts in epidemiology and stomatology, the final version of the questionnaire had acceptable content validity. And the internal consistency of the KAB questionnaire was acceptable (Cronbach's alpha $=0.910$ ).

The knowledge part of powered toothbrush was assessed by 6 single-choice questions, about the knowing of powered toothbrush and its effects on tooth brushing. Each question was assigned a score of 1 , and the total score for this part ranged from 0 to 6 , a high score indicates a higher level of knowledge on the topic. Example of the questions included: "Do you think that powered toothbrush can clear plaque more effectively, compared with manual toothbrush"?

The attitude part of was assessed by 3 single-choice questions on the attitudes of using and recommending powered toothbrush. Each question consisted of three levels with a score ranging from 0 to 2, which imply "certainly not" (score=0), "maybe" (score=1), and "Sure" (score=2). The total score for this item may range from 0 to 6 , and a high score indicates a good attitude towards recommending powered toothbrush. Example of the questions included: "Would you like to recommend powered toothbrushes to others"?

Behaviors regarding powered toothbrush was assessed by 4 single-choice questions on the used and the recommendation powered toothbrush. Each question was assigned a score of 1 , and the total score for this part ranged from 0 to 4 . A high score indicates a good behavior regarding brushing teeth with powered toothbrush. Example of the questions included: "Are you using powered toothbrush to brush your teeth everyday"?

The scores of knowledge, attitude and behaviors were classified into two levels: "need to be strengthen" ( $\leq 60$ percent) and "satisfactory" (>60percent) ${ }^{35}$

The study was performed in accordance with the World Medical Association Declaration of Helsinki and ethics approval was obtained from the Ethical Committee of the Chongqing Medical University. The participation of the respondents was voluntary, and they were included in the study after submitting signed informed consent. 


\section{Quality control}

The investigators were selected from dental students who were willing to participate in this study by an interview. Prior to the survey, the investigators were trained in relevant knowledge and the implementation of the survey. Only the researchers who were familiar with the objectives and methods of this study, as well as having good interview skills and the experience in dealing with potentially sensitive issues were allowed to conduct the survey. Each of the questionnaire was checked to avoid mistakes.

\section{Statistical analysis}

The Statistical Package for Social Sciences (SPSS) software version 19.0 (SPSS Inc., USA) was applied to analyze the data. The descriptive data were expressed as mean \pm standard deviation (SD) or proportions (\%). Chi-square test was performed to test the differences among the categorical variables $\mathrm{A}$ $p<0.05$ was considered statistically significant. Multiple linear regression analysis was used to assess the association between sociodemo graphic and KAB.

\section{Results}

\section{Demographic characteristics of study population.}

A total of 437 doctors were invited to participate the study, 403 valid questionnaires were acquired (from 243 doctors were from non-dental departments and 160 were dentists), the response rate was 92.2 percent. Table 1 showed the demographic characteristics of study population. (Please see Table 1.).

\section{KAB Scores of brushing teeth with powered toothbrush and its inter-association.}

The mean score of knowledge, attitude and behaviors was $3.6 \pm 1.4,3.6 \pm 1.7,1.3 \pm 0.8$, respectively. The levels of KAB were classified into the two categories: "satisfactory" and "need to be strengthen". The proportion of "need to be strengthen" on knowledge, attitude and behaviors was 68.0 percent, 71.0 percent and 80.4 percent, respectively. (Please see Table 2.)

\section{Usage of powered toothbrush}

The usage rate of powered toothbrush was low in doctors (12.2 percent), and no obvious differences between various types of doctors ( $p>0.05$ ). Moreover, it is noteworthy that the usage rate of powered 
toothbrush among dentists was not higher than that among non-dental doctors ( $p>0.05)$ (Please see Table 3.).

\section{Factors Associated with $\mathrm{KAB}$ of brushing teeth with powered toothbrush}

Table 4 showed that doctors from dental department had higher knowledge $(p<0.001)$ and attitude $(p<0.01)$ scores than the doctors from non-dental department, but there were no statistical significance in behaviors scores $(p>0.05)$. Doctors from the district with a higher gross regional product had higher knowledge $(p<0.01)$ and behaviors scores $(p<0.001)$, and doctors from higher-level hospitals had higher knowledge scores $(p<0.01)$. Using powered toothbrush was positively associated with the knowledge $(p<0.001)$, attitude $(p<0.05)$ and behaviors $(p<0.001)$ scores. Gender and age were not associated with KAB scores ( $p>0.05)$. (Please see Table 4.)

\section{Discussion}

The use of powered toothbrush in accordance with the standards may be able to clean teeth more efficiently and better, especially for children with low attention to teeth, low enthusiasm for oral health maintenance, and difficulty in mastering manual brushing techniques. ${ }^{36-38}$ Systematic reviews have demonstrated that powered toothbrush was more effective for removing plaque and reducing gingivitis. 18-19, 39 Moreover, there was no significant cause-and-effect relationship between the use of powered toothbrushes and soft tissue injury, and the reports of soft tissue injury were rare ${ }^{40}$. The safety of using powered toothbrush was reliable, tissue damage was only a small probability of events, and powered toothbrushes are just as safe as manual ones. ${ }^{40}$

This study evaluated the knowledge, attitude and behaviors of doctors regarding brushing teeth with powered toothbrush. The majority of doctors did not have enough knowledge on powered toothbrush, and the usage rate of powered toothbrush was very low in doctors (Only 12.2 percent), suggesting that the cognition or use of powered toothbrush was still at a low level.

Doctors from the district with a higher gross regional product or higher-level hospitals had higher knowledge $(p<0.01)$, probably because they had more opportunity to accept information about the advance of sciences or commercial advertising. However, although dentists tend to display better knowledge of powered toothbrush than doctors from non-dental departments, the usage rate of dentists was also very low and not higher than the usage rate of doctors from non-dental departments, suggesting that the compliance with the knowledge of powered toothbrush among dentists may be poor, probably because dentists may not be sufficiently motivated to engage the selection of toothbrush or they may not 
place enough emphasis on the selection of tools of tooth brushing. Individuals who were using powered had higher scores on knowledge, attitude and behaviors, suggesting that using powered toothbrush may promote the knowledge and attitude in turn, probably because the use of powered toothbrush could inspire the interest to know some relevant knowledge. The level of knowledge, attitude and behaviors of more than two third of individuals were needed to be strengthened, suggesting that health education is needed to improve the cognition of powered toothbrush.

If people follow the scientific method strictly to brush the teeth every time, using manual toothbrush can achieve good cleaning effect as well, however, studies have shown that the majority of people did not brush their teeth systematically, the plaque removal capability of people still tend to be low ${ }^{41-46}$, and brushing teeth incorrectly was particularly common in children ${ }^{47-49}$. Moreover, it should be noted that receiving oral health instruction could improve the effect of powered toothbrush and manual toothbrush on plaque removal ${ }^{50}$, thus, it is necessary for the public to receive enough instructions from doctors to master the systematical skills of tooth brushing and be aware of the tools which may make tooth brushing more effective.

The limitation of this study was that validated questionnaires are rare regarding powered toothbrush, the questionnaire adopted for this study was self-designed by our team after repeated discussions with experts and a pretest. In addition, no information was available about different types of powered toothbrush, which should be considered in future studies.

\section{Conclusions}

The majority of doctors' knowledge, attitude and behaviors regarding powered toothbrush were needed to be strengthened, and the usage rate of powered toothbrush was low in doctors. Specific health education is needed to improve the knowledge, attitude and behaviors regarding powered toothbrush among public, especially for doctors.

\section{Abbreviations}

KAB: Knowledge, attitude, and behaviors; NDDs: Non-dental dentists; SPSS: Statistical Package for Social Sciences.

\section{Acknowledgments}

We would like to acknowledge the support provided by all investigators and participants, and give warmly thank to Prof. Yong Zhao (From School of Public Health \& Management, Chongqing Medical University, Chongqing 400016, China.) for his advices and support in data analysis. 


\section{Declarations}

Competing Interest: Author Yanhao Wang declares that he has no conflict of interest, and author Lin Jiang declares that he has no conflict of interest.

Consent for publication: The authors have given final approval of the version to be published.

Funding: The work was fund by China Oral Health Foundation (2017Chongqing), the funders had no role in study design, data collection and analysis, decision to publish, or preparation of the manuscript.

Ethics approval and consent to participate: All procedures performed in studies involving human participants were in accordance with the ethical standards of the institutional and/or national research committee and with the 1964 Helsinki declaration and its later amendments or comparable ethical standards." Written informed consent was obtained from all individual participants included in the study. This cross-sectional study was approved by the Ethics Committee of Chongqing Medical University (2017.06.23).

Availability of data and materials: The datasets used and/or analyzed during the current study are available from the corresponding author on reasonable request. For privacy reasons, however, individual data allowing for the identification of participants cannot be made available.

\section{Authors' Contribution.}

The authors have made substantial contributions to conception and design of the study. Y. W. and L.J. have been involved in study design and data collection. Y.W. has been involved in and data analysis, L.J. has been involved in data interpretation, Y.W. has been involved in drafting the manuscript.

\section{References}

1. Hu Jinghao, Jiang Wen, Lin Xiaolong, et al. Dental Caries Status and Caries Risk Factors in Students Ages 12-14 Years in Zhejiang, China. Medical Science Monitor. 2018;24:3670-3678.

2. Jeffcoat M K. Prevention of periodontal diseases in adults: strategies for the future. Preventive Medicine, 1994, 23(5):704-708.

3. Xing W. Report of the fourth national oral health survey. Beijing: People's Medical Publishing House, China, 2018, 116-129.

4. Nobbs A H, Jakubovics N S, Jenkinson H F. Stick to Your Gums: Mechanisms of Oral Microbial Adherence. Journal of Dental Research, 2011, 90(11):1271-1278. 
5. Gibbons R J, Houte J V. Bacterial adherence in oral microbial ecology. Annual Review of Microbiology, 1975, 29(1):19-44.

6. Aas J A, Griffen A L, Dardis S R, et al. Bacteria of dental caries in primary and permanent teeth in children and young adults. Journal of Clinical Microbiology, 2008, 46(4):1407-1417.

7. Tanner A C, Haffer C, Bratthall G T, Visconti R A, Socransky S S. A study of the bacteria associated with advancing periodontitis in man. Journal of Clinical Periodontology, 2010, 6(5):278-307.

8. Ranney R R, Best A M, Breen T J, Moore W E, Moore L V. Bacterial flora of progressing periodontitis lesions. Journal of Periodontal Research, 2010, 22(3):205-206.

9. Stoodley Paul, Wefel James, Gieseke Armin, Debeer Dirk, von Ohle Christiane. Biofilm Plaque and Hydrodynamic Effects on Mass Transfer, Fluoride Delivery and Caries. Journal of the American Dental Association, 2008, 139(9):1182-1190.

10. Zenkner JE, Alves LS, de Oliveira RS, Bica RH, Wagner MB, Maltz M. Influence of eruption stage and biofilm accumulation on occlusal caries in permanent molars: a generalized estimating equations logistic approach. Caries Research 2013; 47(3):177-182.

11. ÅSa Lundströum, Johansson L Å, Hamp S E. Effect of combined systemic antimicrobial therapy and mechanical plaque control in patients with recurrent periodontal disease. Journal of Clinical Periodontology, 2010, 11(5):321-330.

12. Al-Shammari Khalaf F, Al-Khabbaz Areej K, Al-Ansari Jassem M, Neiva Rodrigo, Wang Hom-Lay. Risk indicators for tooth loss due to periodontal disease. Journal of Periodontology, 2005, 76(11):19101918.

13. Needleman I, Nibali L, Di I A. Professional mechanical plaque removal for prevention of periodontal diseases in adults--systematic review update. Journal of Clinical Periodontology, 2015, 42(S16):229282.

14. Holmen L, Mejare I, Malmgren B, Thylstrup A. A polarized light and scanning electron microscope study of the effect of Duraphat treatment on in vivo caries. Scand J Dent Res, 2010, 94(6):521-529.

15. Suomi J D, Peterson J K, Matthews B L, Voglesong R H, Lyman B A. Effects of supervised daily dental plaque removal by children after 3 years. Community Dentistry \& Oral Epidemiology, 2010, 8(4):171176. DOI: 10.1111/j.1600-0528.1980.tb01281.x.

16. Zimmermann H, Zimmermann N, Hagenfeld D, Veile Annette Kim Ti-Sun Becher Heiko. Is frequency of tooth brushing a risk factor for periodontitis? A systematic review and meta-analysis. Community Dentistry and Oral Epidemiology, 2015, 43(2):116-127.

17. Dale J W. Toothbrushing frequency and its relationship to dental caries and periodontal disease. Australian Dental Journal, 2010, 14(2):120-123.

18. Williams Karen, Haun Jan, Dockter Kathy, Ferrante Anita, Bartizek Robert D, Biesbrock Aaron R. Plaque removal efficacy of a prototype power toothbrush compared to a positive control manual toothbrush. American Journal of Dentistry, 2005, 18(2):116-120. DOI: 10.1080/00016350310004566.

19. Yaacob Munirah, Worthington Helen V, Deacon Scott A, et al. Powered versus manual toothbrushing for oral health.. Cochrane Database Syst Rev. 2014;6:CD 002281. 
20. Schmidt J C , Zaugg C , Roland Weiger. Brushing without brushing?-a review of the efficacy of powered toothbrushes in noncontact biofilm removal. Clin Oral Investig, 2013, 17(3):687-709.

21. Ashkenazi M, Bidoosi M, Levin L. Factors associated with reduced compliance of children to dental preventive measures. Odontology 2012; 100: 241-248.

22. Davidovich Esti, Ccahuana-Vasquez Renzo Alberto, Timm Hans, et al. Randomised clinical study of plaque removal efficacy of a power toothbrush in a paediatric population. Int J Paediatr Dent. 2017; 27(6): 558-567.

23. Silverman J, Rosivack RG, Matheson PB, et al. Comparison of powered and manual toothbrushes for plaque removal by 4- to 5-year-old children. Pediatr Dent 2004; 26: 225-230.

24. Pihlstrom Bruce L, Michalowicz Bryan S, Johnson Newell W. Periodontal diseases. Lancet. 2005;366(9499):1809-1820.

25. Linden Gerard J, Lyons Amy, Scannapieco Frank A. Periodontal systemic associations: review of the evidence. J Periodontol. 2013;84(4 Suppl):S8-S19.

26. Liu Juan, Cui Li, Yan Xinmin, et al. Analysis of Oral Microbiota Revealed High Abundance of Prevotella Intermedia in Gout Patients. Cell Physiol Biochem. 2018;49(5):1804-1812.

27. Jensen O, Gabre P, Sköld UM, Birkhed D. Is the use of fluoride toothpaste optimal? Knowledge, attitudes and behaviour concerning fluoride toothpaste and toothbrushing in different age groups in Sweden. Community Dentistry and Oral Epidemiology, 2012, 40(2):175-184.

28. Jensen O, Gabre P, Sköld, Ulla Moberg, Birkhed Dowen. Fluoride toothpaste and toothbrushing; knowledge, attitudes and behaviour among Swedish adolescents and adults. Swedish Dental Journal, 2011, 35(4):203-213.

29. Nordstrom A, Birkhed D. Attitudes and behavioural factors relating to toothbrushing and the use of fluoride toothpaste among caries-active Swedish adolescents - a questionnaire study. Acta Odontologica Scandinavica, 2017: 75(7):483-487.

30. Tobias J S. Hospital doctor's role in the Health of the Nation. 1995;310(6984):889.

31. Chantler $C$. The role and education of doctors in the delivery of health care. The Lancet, 1999, 353(9159):1178-1181. DOI: 10.1016/S0140-6736(99)01075-2.

32. Prideaux $D$, Alexander $H$, Bower $A$, et al. Clinical teaching: maintaining an educational role for doctors in the new health care environment. Med Educ. 2000;34(10):820-826.

33. Zhong Jingdong, Gao Jingjing, Liu Chengfang, Huang Jie, Luo Renfu. Quantity-Quality Trade-Off and Early Childhood Development in Rural Family: Evidence from China's Guizhou Province.. Int J Environ Res Public Health. 2019;16(7), 1307.

34. Bettinghaus, E.P. Health promotion and the knowledge-attitude-behavior continuum. Med. 1986, 15(5), 475-491.

35. Ping $\mathrm{H}$, Wenjie $\mathrm{H}$, Ruixue $B$, et al. Knowledge, Attitude, and Behaviors Related to Eating Out among University Students in China. Int J Environ Res Public Health. 2016, 13(7), 696. 
36. Awasthi Prateek, Peshwani Bharti, Tiwari Shilpi, Thakur Ruchi, Shashikiran N D, Singla Shilpy. Evaluation and comparison of the efficacy of low fluoridated and calcium phosphate-based dentifrice formulations when used with powered and manual toothbrush in children with autism.. Contemp Clin Dent. 2015;6(Suppl 1):S188-191.

37. Williams Karen, Ferrante Anita, Dockter Kathy, Haun Jan, Biesbrock Aaron R, Bartizek Robert D. Oneand 3-minute plaque removal by a battery-powered versus a manual toothbrush. J Periodontol. 2004;75(8):1107-1113.

38. McCall JO. The world workshop in periodontics. J Periodontol, 1967, 38(6):555-557.

39. Deacon SA, Glenny AM, Deery C, et al. Different powered toothbrushes for plaque control and gingival health. Cochrane Database Syst Rev, 2010, 8(12):CD004971.

40. Robinson PG, Deacon SA, Deery C, et al. Manual versus powered toothbrushing for oral health. Cochrane Database Syst Rev, 2005, 18(2):CD002281.

41. Deinzer Renate, Ebel Stefanie, Blättermann Helen, Weik Ulrike Margraf-Stiksrud Jutta. Toothbrushing: to the best of one's abilities is possibly not good enough.. BMC Oral Health. 2018;18(1):167.

42. Macgregor I D , Rugg-Gunn A J . Effect of filming on toothbrushing performance in uninstructed adults in north-east England. Community Dentistry \& Oral Epidemiology, 2010, 14(6):320-322.

43. Winterfeld $T$, Schlueter $N$, Harnacke D, et al. Toothbrushing and flossing behaviour in young adultsa video observation. Clinical Oral Investigations, 2015, 19(4):851-858.

44. Albertsson K W, van Dijken J W . Awareness of toothbrushing and dentifrice habits in regularly dental care receiving adults. Swedish Dental Journal, 2010, 34(2):71-78.

45. Harnacke D, Winterfeld T, Erhardt J , et al. What Is the Best Predictor for Oral Cleanliness After Brushing? Results From an Observational Cohort Study. Journal of Periodontology, 2015, 86(1):101107.

46. Eaton K A, Carlile M J. Tooth brushing behaviour in Europe: opportunities for dental public health. International Dental Journal, 2011, 58(S5):287-293.

47. J. Rugg-Gunn, Macgregor I D M . A survey of toothbrushing behaviour in children and young adults. Journal of Periodontal Research, 2010, 13(4):382-389.

48. Deinzer Renate, Cordes Oliver, Weber Julia, et al. Toothbrushing behavior in children - an observational study of toothbrushing performance in 12 year olds. BMC Oral Health. 2019;19(1):68.

49. Paunio P , Rautava $P$, Helenius H , Sillanpää M. Children's poor toothbrushing behavior and mothers' assessment of dental health education at well-baby clinics. Acta Odontologica Scandinavica, 1994, 52(1):36-42.

50. Van der Weijden G A, Timmerman M F, Nijboer A, Lie M A, Van der Velden U. A comparative study of electric toothbrushes for the effectiveness of plaque removal in relation to toothbrushing duration. Journal of Clinical Periodontology, 1993, 20(7):476-481.

\section{Tables}


Table 1. Demographic characteristics of the study participants $(\mathrm{N}=403)$

\begin{tabular}{|c|c|c|c|}
\hline \multicolumn{2}{|c|}{ Characteristics } & \multicolumn{2}{|c|}{ Participants } \\
\hline & & $n$ & $(\%)$ \\
\hline \multirow[t]{2}{*}{ Gender } & Male & 116 & 28.8 \\
\hline & Female & 287 & 71.2 \\
\hline \multirow[t]{4}{*}{ Age } & $<30$ years & 238 & 59.1 \\
\hline & $30 \sim 44$ years & 103 & 25.6 \\
\hline & $45 \sim 60$ years & 50 & 12.4 \\
\hline & $>60$ years & 12 & 3.0 \\
\hline \multirow[t]{2}{*}{ Department } & Non-dental & 243 & 60.3 \\
\hline & Dental & 160 & 39.7 \\
\hline \multirow[t]{4}{*}{ Hospital type } & Tertiary hospitals & 126 & 31.3 \\
\hline & Secondary hospitals & 162 & 40.2 \\
\hline & Community hospitals & 24 & 6.0 \\
\hline & Private clinics & 91 & 22.6 \\
\hline \multirow[t]{5}{*}{ District } & Yuzhong & 117 & 29.0 \\
\hline & Banan & 68 & 16.9 \\
\hline & Qijiang & 107 & 26.6 \\
\hline & Wulong & 55 & 13.6 \\
\hline & Fengdu & 56 & 13.9 \\
\hline
\end{tabular}

Table 2. Distribution of $\mathrm{KAB}$ on powered toothbrush $(\mathrm{N}=403)$

\begin{tabular}{lccc}
\hline & Knowledge & Attitude & Behaviors \\
& $n(\%)$ & $n(\%)$ & $n(\%)$ \\
\hline Need to be strengthen & $274(68.0)$ & $286(71.0)$ & $324(80.4)$ \\
Satisfactory & $129(32.0)$ & $117(29.0)$ & $79(19.6)$ \\
\hline
\end{tabular}

Note: The scores of knowledge, attitude and behaviors were classified into two levels: "need to be strengthen" ( $\leq 60$ percent) and "satisfactory" (>60percent) 
Table 3. Usage of powered toothbrush $(\mathrm{N}=403)$

\begin{tabular}{|c|c|c|c|c|c|}
\hline \multicolumn{2}{|c|}{ Characteristics } & $\begin{array}{c}\text { Use it } \\
\text { N1 (\%) }\end{array}$ & $\begin{array}{c}\text { Not use it } \\
\text { N2 (\%) }\end{array}$ & $X^{2}$ & $P$ \\
\hline \multirow[t]{2}{*}{ Gender } & Male & 19 (16.4) & 97 (83.6) & 2.717 & 0.099 \\
\hline & Female & $30(10.5)$ & 287 (89.5) & & \\
\hline \multirow[t]{4}{*}{ Age } & $<30$ years & $24(10.1)$ & 238 (89.9) & 2.436 & 0.487 \\
\hline & 30 44 years & $15(14.6)$ & $103(85.4)$ & & \\
\hline & $45 \sim 60$ years & $8(16.0)$ & $50(84.0)$ & & \\
\hline & $>60$ years & $2(16.7)$ & $12(83.3)$ & & \\
\hline \multirow[t]{2}{*}{ Department } & Non-dental & 30 (12.3) & $243(87.7)$ & 0.020 & 0.888 \\
\hline & Dental & 19 (11.9) & $160(88.1)$ & & \\
\hline \multirow[t]{4}{*}{ Hospital type } & Tertiary hospitals & $19(15.1)$ & $126(84.9)$ & 1.546 & 0.672 \\
\hline & Secondary hospitals & 17 (10.5) & $162(89.5)$ & & \\
\hline & Community hospitals & $3(12.5)$ & $24(87.5)$ & & \\
\hline & Private clinics & $10(11.0)$ & $91(89.0)$ & & \\
\hline \multirow[t]{5}{*}{ District } & Wulong & $3(5.5)$ & $55(94.5)$ & 7.238 & 0.124 \\
\hline & Fengdu & $8(14.3)$ & $56(85.7)$ & & \\
\hline & Qijiang & $10(9.3)$ & 107 (90.7) & & \\
\hline & Banan & $7(10.3)$ & 68 (89.7) & & \\
\hline & Yuzhong & $21(17.9)$ & $117(82.1)$ & & \\
\hline
\end{tabular}

Table 4. Multiple linear regression analysis with Demographic characteristics and KAB. 


\begin{tabular}{lcccccccccc}
\hline Variables & \multicolumn{3}{c}{ Knowledge } & \multicolumn{3}{c}{ Attitudes } & \multicolumn{3}{c}{ Behaviors } \\
\cline { 2 - 10 } & Beta & $S E$ & $p$ & Beta & $S E$ & $p$ & Beta & $S E$ & $p$ \\
\hline Gender $^{\text {a }}$ & 0.023 & 0.140 & 0.613 & 0.085 & 0.183 & 0.086 & 0.056 & 0.057 & 0.091 \\
Age $^{\text {b }}$ & -0.025 & 0.178 & 0.575 & -0.092 & 0.233 & 0.070 & -0.004 & 0.073 & 0.908 \\
Department $^{c}$ & 0.312 & 0.133 & $0.000^{*}$ & 0.162 & 0.174 & $0.002^{*}$ & -0.004 & 0.054 & 0.902 \\
District $^{\mathrm{d}}$ & 0.152 & 0.046 & $0.001^{*}$ & 0.087 & 0.061 & 0.082 & 0.127 & 0.019 & $0.000^{*}$ \\
Hospital $^{\mathrm{e}}$ & 0.150 & 0.059 & $0.002^{*}$ & 0.088 & 0.078 & 0.091 & -0.038 & 0.024 & 0.274 \\
Using or not $^{\mathrm{f}}$ & 0.241 & 0.190 & $0.000^{*}$ & 0.126 & 0.249 & $0.010^{*}$ & 0.752 & 0.078 & $0.000^{*}$ \\
\hline
\end{tabular}

Note: "Beta" indicates standardized partial regression coefficient; “SE” indicates standard error. ${ }^{a}$ Gender (Male=0, Female=1) ${ }^{\text {b }}$ Age $($ Not older than 44=0, Older than 44=1) c Department (Non-dental=0, Dental=1) d District (Wulong=0, Fengdu=1, Qijiang=2, Banan=3, Yuzhong=4) e Hospital (Private clinics=0, Community hospitals=1, Secondary hospitals=2, Tertiary hospitals=3) ${ }^{\mathrm{f}}$ Using or not (Not using powered toothbrush=0, Using powered toothbrush $=1) * p<0.05$ indicates significant difference. 